\title{
Introducing BDJ Team's reader panel
}

Our reader panel will be invited to make suggestions for articles, review books, comment on articles that are going to be published in BDJ Team, and provide feedback on dental events such as conferences and tradeshows. You may recognise some of these stunners from past Vital covers!

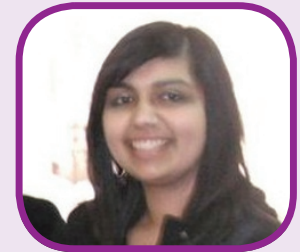

Asma Chaudhri

Qualified dental nurse tutor/

Part-time dental nurse

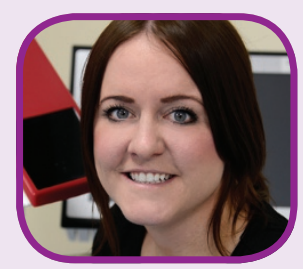

Christine Smethurst

Auxiliary dental tutor

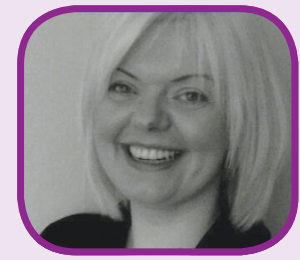

Claire Deegan

Practice support manager and Dental nurse tutor

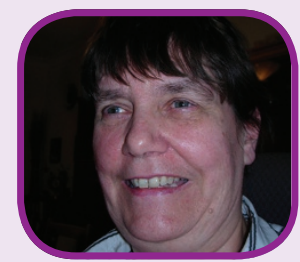

Di Etherington

Dental nurse

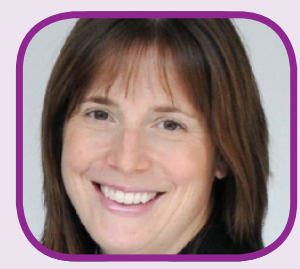

Diane Cox

Dental nurse and Patient care coordinator

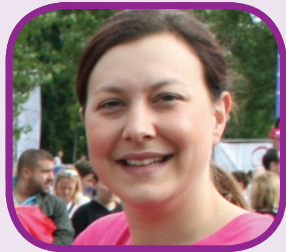

Felicity Cleaver

Dental practice manager and Coach

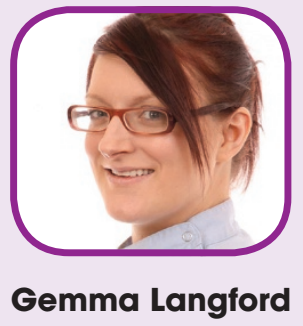

Dental hygienist

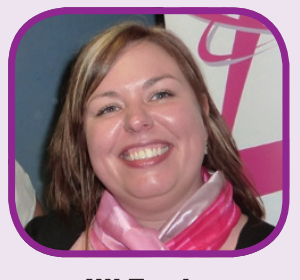

Jill Taylor

Key client consultant (Scotland)

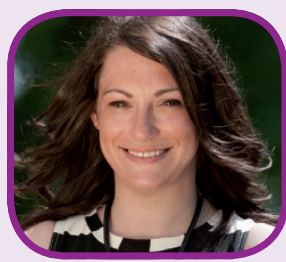

Melanie Joyce

Dental therapist/trainer

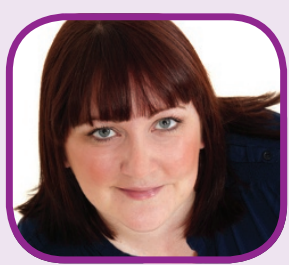

Rachael England

Dental hygienist

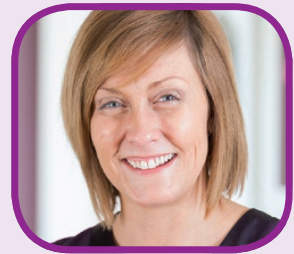

Rachel Hughes

Clinical treatment coordinator/ Training manager

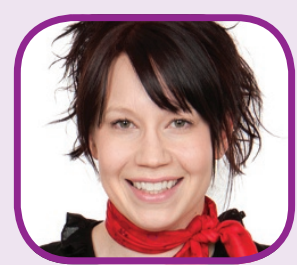

Rhiannon Pounds

Dental nurse,

Treatment coordinator

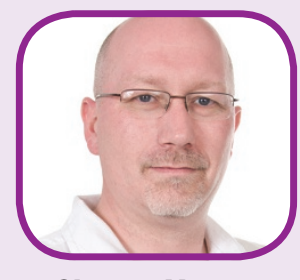

Shaun Howe

Dental hygienist

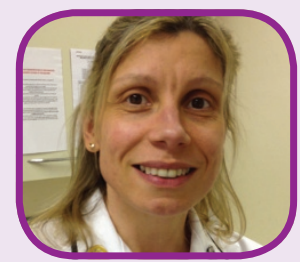

Steph Horner

Dental nurse/

Decontamination lead

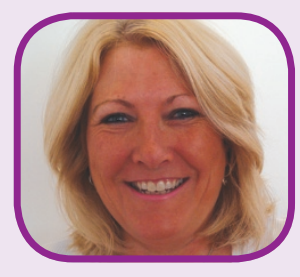

Jacqui Elsden

Dental Education Facilitator 